\title{
Using marketing principles for healthcare development
}

\author{
Edward Dickinson
}

In this paper I examine the scope for using marketing principles in health service development, which, for the purposes of this paper, is putting knowledge into action - new technologies, new services, or new organisational arrangements. At the moment both central government and those working in the NHS research and development system recommend clinical guidelines as a prime means of moving knowledge into practice. ${ }^{12}$ Therefore, I will use the case of clinical guidelines to bring the ideas of marketing to life, using examples from the royal college's development programme in the health care of elderly people. However, the principles described could be used for any other approach to health service development. I will first consider the marketing concept as the basis for the principles of marketing and then introduce the idea that knowledge can be made into products. I will then review the central challenge of moving towards science based practice and discuss six principle marketing activities, ending with the existing opportunities for practical use of the marketing concept.

\section{The marketing concept}

Modern marketing is based on the marketing concept, which is, in essence, succeeding by finding out the needs of target markets and satisfying them. ${ }^{3}$ Using this concept requires a market focus and orientation towards the consumer. Neither of these are of prime concern to organisations which base their activities on the concepts of production, product, and selling. These concentrate respectively on having the best production system, making the best products, and aggressive selling. Although these approaches have been used in the past, most forward thinking firms now use the marketing concept to reap success, marketing being increasingly viewed as a core business function. However, in this paper I am not suggesting that health care should be run as a business but rather that valuable theory and experience from the business world could be adapted for health services development. Recent commentators have suggested that one aspect of marketing the theory of the diffusion of innovations could be used. ${ }^{24}$ This partial approach has, however, been tried and had only limited success. $^{56}$ One attraction of using the marketing concept and principal activities is that it provides a framework for a comprehensive approach.

\section{"Knowledge products"}

Good marketing begins with a need rather than with a preconceived specification for a product. Knowledge can be regarded as a raw material comprising published research output, systematic overviews (such as those to be produced by the Cochrane Collaboration), and perhaps handed down clinical wisdom (fig 1). From this raw material "knowledge products" can be produced according to the needs of consumers in relation to developing clinical practice. These needs can be considered as a hierarchy of increasing specificity (table 1), springing from the core need for up to date knowledge. These needs may prove to be complex - for example, a recent survey showed that general practitioners have individual needs in relation to clinical guidelines for the management of asthma. ${ }^{8}$ This is not surprising, and the same can be expected of different stakeholders in clinical practice. It implies a need to balance the advantages of mass production with a need for customisation (see below). In discussing knowledge products for developing clinical practice the ultimate purpose to which such products will be put must be borne in mind for example, one key purpose is enhancing clinical decision making.

\section{The challenge}

The central challenge in health service development is basing practice on knowledge. At the moment this tends to be conceptualised in a top down fashion - what would be called product push in industry. It is expressed in phrases such as "moving knowledge into practice." There is ample evidence either that this does not happen or that it happens slowly. Although the publication of some clinical trials has resulted in measurable changes in medical practice, ${ }^{9}$ others have had no effect. ${ }^{10}$ There is ample evidence of delayed uptake in relation to premature labour, ${ }^{11}$ use of anticoagulants, ${ }^{12}$ and treatment of asthma. ${ }^{13}$ An often quoted example is the use of thrombolysis for myocardial infarction. Persuasive evidence that this is an effective intervention has existed for many years, ${ }^{14}$ but despite large trials ${ }^{15}$ and broad acceptance, ${ }^{16}$ this proved intervention is still not used ${ }^{17}$ and inappropriate agism in its use exists. ${ }^{18}$ Improving the situation is one of the central planks of the new NHS research and development strategy. ${ }^{19}$ Researchers have been encouraged to give some thought to implementing their findings, ${ }^{2}$ and those applying for NHS grants must now indicate how their findings might be implemented. The 

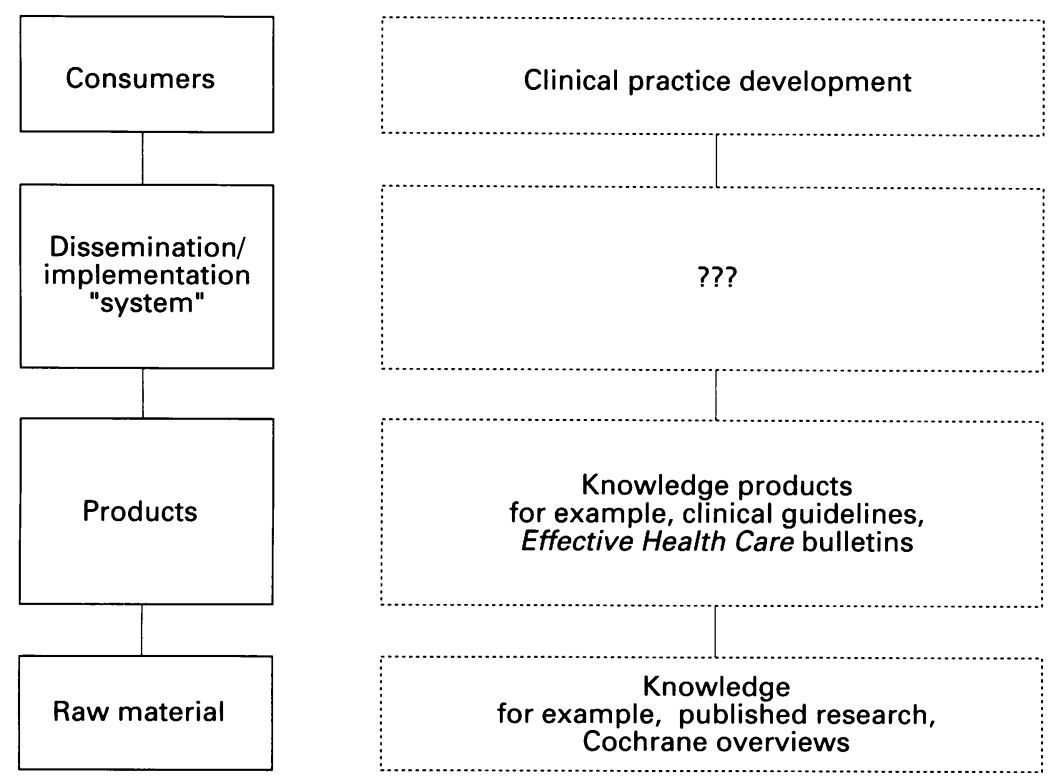

Fig 1 Clinical practice development by satisfying knowledge needs with knowledge products

consumers of knowledge products, however, seem to have been little consulted.

Currently, clinical guidelines form the central thrust for implementation along with publications such as the Effective Health Care bulletins. ${ }^{20}$ Yet, there has been considerable doubt and cynicism about the role of guidelines $^{21}$; some experiences have been positive $^{22}$ but others have been less encouraging. ${ }^{23} \mathrm{~A}$ recent systematic overview suggested that in general clinical guidelines work with provisos, ${ }^{24}$ but it has been asserted that many more sets of guidelines have been drawn up than have been implemented. ${ }^{25}$ Surprisingly, despite fears of cookbook medicine, control of medical practice, and medicolegal worries, physicians seem to have a generally favourable view of clinical guidelines. ${ }^{26}$ Although there have been major changes in the way that clinical guidelines are produced, the general view seems to be that such knowledge products should be defined by their producers. For example, a recent article described what seems to be a primarily top down approach for implementing research findings, ${ }^{2}$ suggesting a product focus. The

Table 1 Hierarchy of knowledge needs

\begin{tabular}{|c|c|c|}
\hline Hierarchy level & Description & Example \\
\hline Need family & Core need & $\begin{array}{l}\text { Up to date knowledge for } \\
\text { clinical practice } \\
\text { development }\end{array}$ \\
\hline Product family & $\begin{array}{l}\text { All the product classes that can satisfy a } \\
\text { core need }\end{array}$ & Knowledge products \\
\hline Product class & $\begin{array}{l}\text { A group of products within the product } \\
\text { family with functional coherence }\end{array}$ & $\begin{array}{l}\text { Expert practice support } \\
\text { materials }\end{array}$ \\
\hline Product line & $\begin{array}{l}\text { A group of products within a product } \\
\text { class with similar characteristics }\end{array}$ & Clinical guidelines \\
\hline Product type & $\begin{array}{l}\text { Items within a product line that share } \\
\text { one of several forms of the product }\end{array}$ & For the care of asthma \\
\hline Brand & $\begin{array}{l}\text { Name associated with one or more } \\
\text { items in the product line }\end{array}$ & British Thoracic Society \\
\hline Item & $\begin{array}{l}\text { A distinct unit within a brand or } \\
\text { product line }\end{array}$ & $\begin{array}{l}\text { Guidelines for the } \\
\text { management of asthma: a } \\
\text { summary }^{\overline{7}}\end{array}$ \\
\hline
\end{tabular}

marketing concept maintains that greater success would be achieved with a customer focus. Recent experiences seem to show the vast superiority of the marketing efforts of the pharmaceutical industry over circulation of an Effective Health Care bulletin in influencing prescribing of a new class of antidepressants. ${ }^{27}$ This reinforces the idea that the marketing approach has major advantages. Certainly, success has accrued to organisations which have a strong marketing orientation such as Marks and Spencer and British Airways. As discussed below, such a comprehensive approach recognises that there are many ingredients to successful change. A multipronged approach has been shown to work in reducing inappropriate laboratory requests. ${ }^{28} \mathrm{~A}$ further advantage is that the marketing approach assists in the management of the process.

\section{Principal marketing activities}

Six main marketing activities are used to implement the marketing concept; I will discuss each in relation to clinical guidelines.

\section{ANALYSING OPPORTUNITIES}

Before embarking on production, the producer should analyse the chances of success. This requires an information system that gathers together information from previous ventures, intelligence, and formal market research. Any of a variety of models may be used to evaluate the situation accordidng to the environment faced, the potential markets, buyer behaviour, and the activities of competitors. A simple SWOT (strengths, weaknesses, opportunities, threats) analysis for clinical guidelines is shown in figure 2 .

\section{SELECTING TARGET MARKETS}

Mass marketing has now been replaced by selective marketing. This is done by assessing the likely demand and segmenting the market. Segmentation is the process of dividing up the population of potential consumers on the basis of common characteristics so that one group of consumers with a common identity can be targeted with a tailored approach. Different segments may be more or less attractive in the first instance; some may represent higher demands; some may be more accessible; some may be easier to identify. With respect to clinical guidelines, segmentation might be carried out by user group (purchaser, provider, consumer), specialty, or discipline or by using a focus such as the clinical director or purchasing lead. An obvious approach is to work closely with a specialty, members of which are fairly identifiable.

\section{DEVISING MARKETING STRATEGIES}

A marketing strategy defines the broad approaches to the selected market segments. Three aspects of the strategy are of particular importance: positioning the product, developing the product, and managing the product life cycle.

Positioning - Products are positioned so that they occupy a distinctive and valued place in 


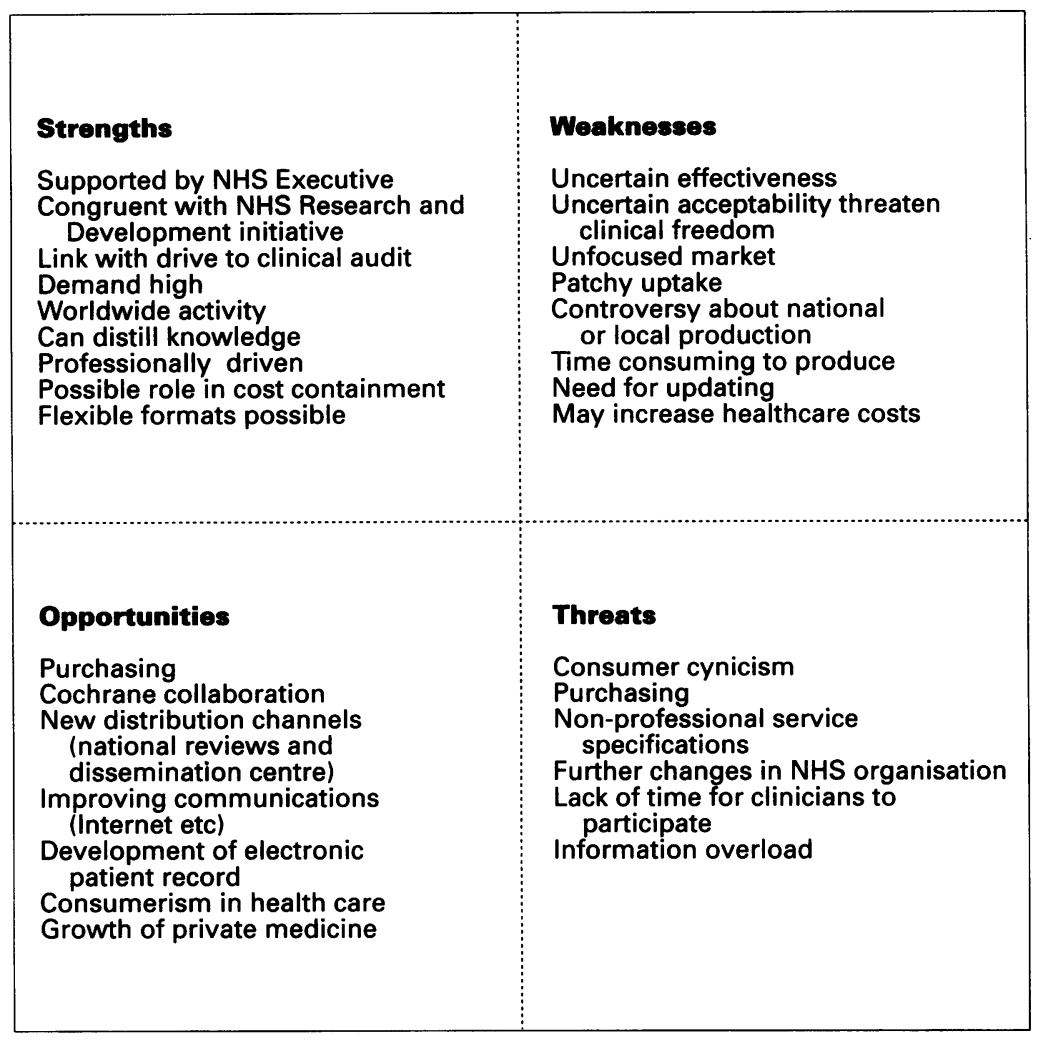

Fig 2 SWOT (strengths, weaknesses, opportunities, threats) analysis for producing clinical guidelines a new description such as expert practice support may be more effective.

Product development - Decisions must be made about liaison with consumers in the phase of product development. This has now become common practice in many industries. Boeing involved its customers heavily in the development of its latest aircraft. We now seek to do this with clinical guidelines development; a range of different consumers - patients, purchasers, providers, and policy makers. We also seek the participation of all the care disciplines, both experts and grass roots clinicians, and in the different parts of the United Kingdom. Some are involved in making the product and often they are keen to participate in pilot testing and researching the effectiveness of the recommended clinical guidelines. ${ }^{17}$ In effect, they may become product champions, whose word of mouth recommendation has immeasurable worth.

Managing the product life cycle - An approach to managing the product through its life cycle must be devised because everything becomes out of date. One approach is to produce new formats. For example, clinical guidelines that started life as reports could be produced as software, ${ }^{34}$ as videos, or on CD ROM. They may also be adapted over time for different market segments or new markets.

\section{PLANNING MARKETING PROGRAMMES}

Planning a marketing programme is deciding on the "nuts and bolts," or the implementation-dissemination phase in figure 1. This comprises the design of a "marketing mix," or the recipe for how the four main marketing tools - product, price, place, and promotion (table 2) - will be used. Apart from an action plan, this also provides a framework for allocating resources, responsibilities, and communication.

Price may not be a prime consideration for clinical guidelines, but guidelines are often sold. A strategy is needed. Should the members of a producer organisation get free copies? Will those who pay a price attach more value to what they have bought?

Place refers to distribution. The importance of the distribution of clinical guidelines has been emphasised in a study of guidelines for the management of head injury. ${ }^{35}$ Although new channels of distribution are now opening up such as the information superhighway, ${ }^{36}$ distribution through existing systems is patchy and uncertain.

Promotion - There are many opportunities for promotion in the health sector such as journals, books, conferences, etc. In addition, direct communication is possible through membership organisations. We have established a National Research and Development Network in Geriatric Medicine to facilitate such activities. There is a newsletter entitled Linker and a growing group of local link people, who are consultant geriatricians with an interest in service development. In due course, the network will expand to cover the other disciplines and sectors of care. For many organisations, the sales force provides the key

\begin{tabular}{llll} 
Table 2 & Components of the marketing mix & & \\
\hline Product & Price & Promotion & Place \\
\hline Brand name & Payment & Advertising & Channels \\
Packaging & Discounts & Sales promotion & Locations \\
Service & Subscriptions & PR and publicity & Delivery \\
Features & Bundles & Selling & Stocks \\
Quality & Cost-benefit in use & Direct marketing & Speed of order \\
\hline
\end{tabular}


Clinical practice development

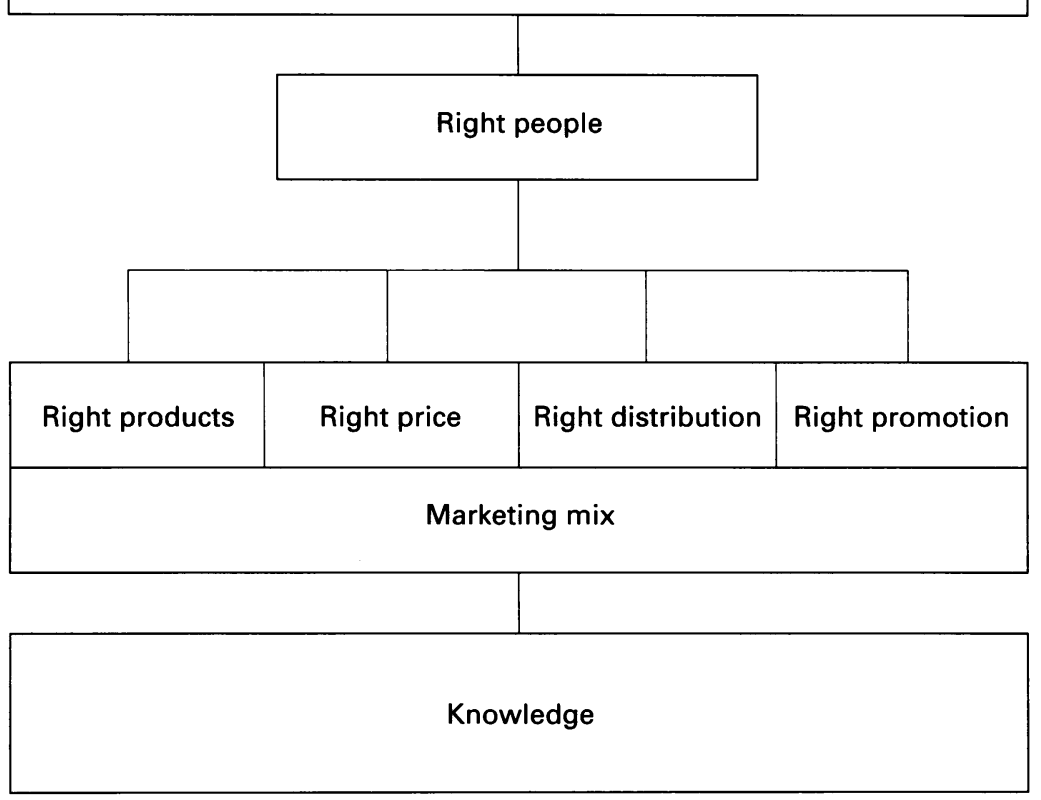

Fig 3 Using marketing approaches for developing clinical practice

element of personal promotion. An analogy in the health service is the role of facilitators in service development. ${ }^{37}$ Figure 3 shows the role of the marketing mix in clinical practice development and identifies the target segment as the "right people" to remind us that we must communicate with consumers who will use the product.

ORGANISING, IMPLEMENTING, AND CONTROLLING

The marketing effort must be properly organised so that it can be implemented accurately. In industry this can be organised by function (having a marketing department), according to product grouping, by consumer groups, or by geography. As far as clinical guidelines are concerned, it would probably be best to begin by instilling the marketing concept throughout the producer organisation. During the implementation stage, control is required and the information for this may also be used as a marketing information system as I mentioned in the first part of this paper. Control is needed to measure results and effectiveness and remind the organisation of its aims.

WORKING WITHIN A STRATEGIC FRAMEWORK As can be seen, the use of the marketing concept is an activity based on strategic principles. Thus, effective working also needs a strategic framework. In the commercial world a key influence on the successful marketing function would be a close fit with overall corporate objectives and strategy. Indeed, in firms which closely espouse the marketing concept, marketing considerations are often central to corporate strategy and may shape the corporate mission. This would apply to clinical guidelines, and we have found it extremely useful for developing a programme of work on the health care of elderly people.

\section{Pathways to using marketing principle}

Several opportunities exist for using the marketing concept to achieve health service development. Firstly, there seems to be a need for a model for helping knowledge uptake into practice; several have been proposed, but the marketing model seems to be more fully embracing than others. ${ }^{38}$ Secondly, adopting the marketing model means that the health service can learn from the world of business. Thirdly, the use of a business concept is broadly compatible with the apparent political imperative for running the health service along business lines. As the management of the health service is strengthened, the use of the marketing concept is an idea that new generations of managers will have come across. Fourthly, the use of the marketing concept is congruent with the growing consumerisation of the health service. ${ }^{39}$ Finally, there is clearly a growing interest in science based care, and this is being fostered through the NHS research and development initiative ${ }^{19}$ and the establishment of the NHS reviews and dissemination centre. This will foster much greater demand for knowledge products. In our work in health care of elderly people, we have found that surveys of consumers and local visits to services have been an excellent way of introducing customer focus in clinical guidelines development. In Anglia and Oxford region this type of approach has resulted in the GRiPP (getting research into practice and purchasing) initiative, which echoes several aspects of the marketing approach. ${ }^{40}$

\section{Conclusion}

The marketing concept and the associated principal activities seem a powerful tool for devising effective approaches to developing the health service within a unifying framework. I have concentrated on the implementation of clinical guidelines, but these ideas would also be applicable to other aspects of health service development such as evidence based education programmes, computerised decision support systems, or an electronic patient record. Although the very word marketing, with its inaccurate connotations of selling, may put off health professionals, use of the marketing concept has gains for them. For example, it puts them in a central position in developing clinical practice rather than making them targets for exhortation and control. What is suggested will require focused use of resources, but this is likely to be repaid in streamlining and speeding up clinical practice development, with resultant savings in inappropriate care and the delivery of higher quality care.

The Research Unit of the Royal College of Physicians is supported by grants from the Wolfson and Welton Foundations, by other charitable donations, and by a grant from the Department of Health. The programme of research and development in the health care of elderly people is additionally supported by Private Patients Plan Medical Trust.

1 NHS Management Executive. Improving clinical effectiveness. Leeds, 1993 (EL (93) 115.) 
2 Haines A, Jones RG. Implementing the findings of research BMF 1994;308:1488-92.

3 Kotler P. Marketing management: analysis, planning, implemen tation and control. Englewood Cliffs: Prentice Hall, 1991.

4 Stocking B. Promoting change in clinical care. Quality in Health Care 1992;1:56-60

5 Hodnett E, Kaufman K, O'Brien-Pallas L, Chipman M. A strategy to promote research-based nursing care: effects on childbirth outcomes. In: Proceedings of the second international Cochrane colloquium. Hamilton: Canadian Cochrane Network and Centre, 1994.

6 Lomas J, Enkin M, Anderson G M, Hannah W J, Vayda E, Singer J. Opinion leaders versus audit and feedback to implement practice guidelines. $\Im A M A$ 1991;265:2202-7.

7 British Thoracic Society and others. Guidelines for the management of asthma: a summary. BMf 1993;306:776-82.

8 Armstrong D, Fry J, Armstrong P. General practitioners' views of clinical guidelines for the management of asthma. views of clinical guidelines for the management of asthma. 6:199-202

9 Lamas GA, Pfeffer MA, Hamm P, Wertheimer J, Rouleau $\mathrm{J}-\mathrm{L}$, Braunwald E, for the SAVE investigators. Do the results of randomised clinical trials of cardiovascular drugs influence medical practice? $N$ Engl Med $\mathcal{J}$ 1992;327:241-7.

10 Chalmers TC. Impact of controlled trials on practice of medicine. Mt Sinai ₹ Med 1974;41:753-9.

11 Donaldson L. Maintaining excellence. BMF 1992;305: 1280-4.

12 Laverick MD, Croal SA, Mollan RAB. Orthopaedic surgeons and thromboprophylaxis. $B M \mathcal{F} 1991 ; 303: 549-50$.

13 Jones $\mathrm{K}$. Asthma care in general practice - time for revolution? Br $\mathcal{F}$ Gen Pract 1991;41:224-6.

14 Antman E, Lau J, Kupelnick B, Mosteller F, Chalmers I. $A$ comparison of the results of meta-analysis of randomised controlled trials and recommendations of randomised controlled trials and recomm

15 ISIS-2 (Second International Study of Infarct Survival) Collaborative Group. Randomised trial of intravenous streptokinase, oral aspirin, both or neither among 17,187 cases of suspected acute myocardial infarction: ISIS-2. Lancet 1988;ii:349-60.

16 Collins R, Julian D. British Heart Foundation surveys (1987 and 1989) of United Kingdom treatment policies for acute myocardial infarction. Br Heart $\mathcal{f} 1991 ; 66: 2505$.

17 Ketley D, Woods KL. Impact of clinical trials on clinical practice: example of thrombolysis for acute myocardial infarction. Lancet 1993;342:891-4.

18 Dudley NJ, Burns E. The influence of age on policies for admission and thrombolysis in coronary care units in the United Kingdom. Age Ageing 1992;21:95-8.

19 Department of Health. Research for health. London: $\mathrm{DoH}$ 1993.

20 Effective Health Care Bulletin. The management of depression in primary care. Leeds: School of Public Health University of Leeds, 1993. (Bulletin No 5.)

$21 \mathrm{McD}$ onald CJ, Overhange JM. Guidelines you can follow and can trust. An ideal and an example. $\mathscr{f} A M A$ 1994;271:872-3.
22 Oakeshott P, Kerry SM, Williams JE. Randomised controlled trial of the effect of the Royal College of Radiologists's guidelines on general practitioners' referrals for radiographic examination. $\mathrm{Br} \mathcal{F}$ Gen Pract 1994;44:197-200.

23 Lomas J, Anderson GM, Domnick-Pierre K, Vayda E, Enkin MW, Hannah WJ. Do practice guidelines guide practice? The effect of a consensus statement on the practice of physicians. $N$ Engl f Med $1989 ; 321: 1306-1$.

24 Grimshaw JM, Russell IT. Effect of clinical guidelines on medical practice: a systematic review of rigorous evaluations. Lancet 1994;342:1317-22.

25 Delamothe T. Wanted: guidelines that doctors will follow. $B M F$ 1993;307:218.

26 Tunis SR, Hayward RSA, Wilson MC, Rubin HR, Bass EB Johnston $\mathrm{M}$, et al. Internists' attitudes about clinica practice guidelines. Ann Intern Med 1994;120:956-63.

27 Freemantle N, Mason J, Watt I. Implementing the findings from systematic overviews: has information on the effectiveness and cost-effectiveness of SSRIs changed practice? In: Proceedings of the second international Cochrane colloquium. Hamilton: Canadian Cochrane Network and Centre, 1994

28 Barefoot D, Hayling A. Inappropriate use of laboratory services: long term combined approach to modify request patterns. $B M \mathcal{F}$ 1990;301:1305-7.

29 Royal College of Physicians and British Geriatrics Society. High quality long term care for elderly people. London: RCP, 1992

30 Research Unit, Royal College of Physicians. The CARE scheme (continuous assessment review and evaluation). RCP, 1992.

31 Research Unit, Royal College of Physicians and British Geriatrics Society. Geriatric day hospitals. Their role and guidelines for good practice. London: RCP, 1994

32 Research Unit, Royal College of Physicians. Clinical audit scheme for geriatric day hospitals. London: RCP, 1994.

33 From research to practice (editorial). Lancet 1994;344: 417-8.

34 Royal College of Physicians, UK Stroke Audit Group. Stroke audit package. London: RCP, 1994.

35 Madhock R, Thomson RG, Mordue A, Mendelow AD, Barker J. An audit of distribution and use of guidelines for management of head injury. Quality in Health Care 1993;2:27-30.

36 Laporte RE. Global public health and the information superhighway. $B M Y$ 1994;308:1651-2

37 Fullard E, Fowler G, Gray JAM. Facilitating prevention in primary care. $B M \mathcal{F}$ 1984;289:1585-7.

38 Lomas J. Teaching old (and not so old) docs new tricks: effective ways to implement research findings. Hamilton: McMaster University, 1993.

39 Department of Health. The patient's charter. London: HMSO, 1991

40 Anglia and Oxford Regional Health Authority. Getting research into practice and purchasing (GRiPP). Four counties approach. Oxford: NHS Executive Anglia and Oxford, 1994. (Resource pack (June 1994).) 